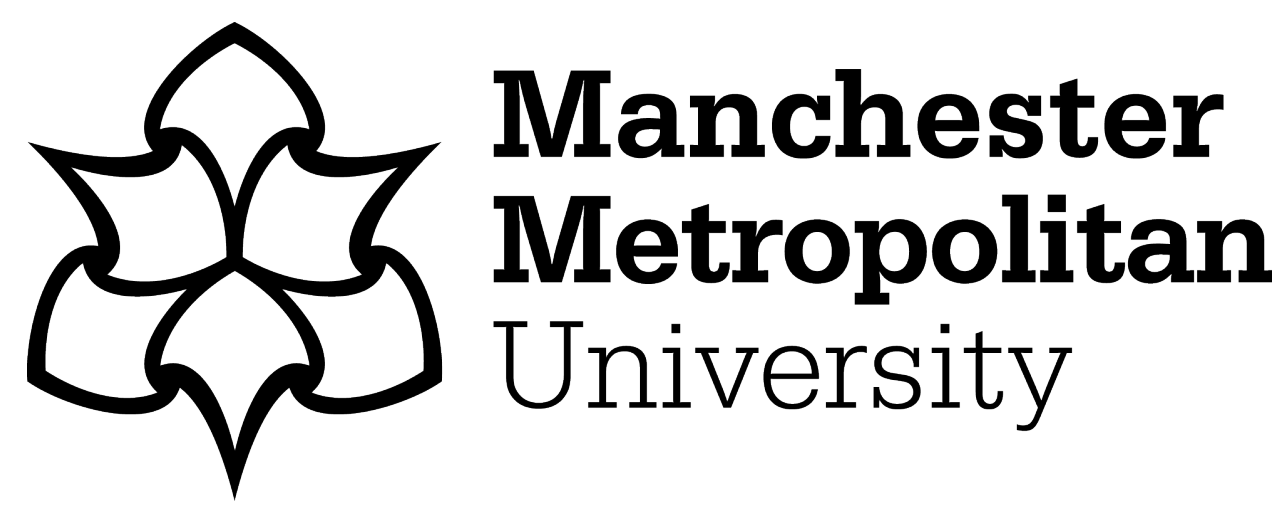

Mackintosh, C, Griggs, G and Tate, R (2019) Understanding the growth in outdoor recreation participation: an opportunity for sport development in the United Kingdom. Managing Sport and Leisure, 23 (4-6). pp. 315-335. ISSN 2375-0472

Downloaded from: https://e-space.mmu.ac.uk/626327/

Version: Accepted Version

Publisher: Taylor \& Francis

DOI: https://doi.org/10.1080/23750472.2019.1595093

Please cite the published version 


\section{Understanding the growth in outdoor recreation participation: an opportunity for sport development in the United Kingdom.}

\section{Introduction}

Participation in physical activities which are alternative or adaptations to traditional mainstream activities have increased rapidly across both North America and Europe in the last decade (Booth and Thorpe, 2007; Hindley, 2018; Sport England, 2016, 2017; Tomlinson et al, 2005), with "increased visibility across public and private space" (Gilchrist and Wheaton, 2011: 113). Within the UK this represents a significant cultural shift where such activities have already both challenged and replaced traditional team sports (Booth and Thorpe, 2007; Green, 2010; Griggs, 2012; Howell, 2008; L'Aoustet and Griffet, 2001). The concern of this paper is with that of the shifts and growth in outdoor recreation participation. Likewise, the outdoor recreation sector was estimated to be worth an estimated $£ 21$ billion in 2012/13 (Comley and Mackintosh, 2014) and an estimated 3.12 billion visits to the great outdoors in 2014-15 (SRA, 2017). The wider European outdoor sector also experienced considerable growth in 2017, according to the European Outdoor Group (EOG) State of Trade report (OIA, 2019). This State of Trade report indicates that the wholesale outdoor market grew by 7.2 per cent in value and 6.7 per cent in volume with the wholesale outdoor market worth $€ 5.86 \mathrm{bn}$ (OIA, 2019). The sector is now acknowledged by various government departments in the United Kingdom (UK) as fundamental to delivering central government cross cutting goals in health, education and the economy. Later in this paper the size of individual aspects of sports and physical activities in the broader outdoors sector will be presented. In recent years The Outdoor Industries Association (OIA) report (2015) established that using MENE data from 2013/14 the outdoor recreation sector has grown with an overall upward trend in visits taken for health or exercise. This motivation was cited for around two-fifths of visits taken in 2013/14. Furthermore, the OIA suggest the British Mountaineering Council reported an increase in climbing competitions (18\% increase from 2012 to 2013). It was also illustrated by Sport England that Snowsport England recently reported a $12 \%$ increase at domestic slopes for the period February to April 2013 to 2014 and a 11\% increase for the period May to August 2013 to 2014. As a wider proxy measure of growth the OIA report (2015) highlights The Mountain Training Association has grown 15\% in 2014-2015 demonstrating an example of the growth in independent niche providers. 
This paper will consider the underlying drivers that are shaping the potential growth in the outdoor recreation field as an area of restorative health policy in the UK (DCMS, 2015; DEFRA, 2017). The paper outlines underlying developments in this area of sport policy as part of a shift towards the adaptation of traditional sporting formats, styles and cultures during an era of 'second modernity'. This conceptual term will be discussed in more detail later after we examine the UK outdoor recreation sector. The paper is not intended as a comprehensive chronological historical map of sport policy in the subfield of outdoor recreation. However, the paper does have the central aim of examining the key societal and individual factors that underpin the growth in outdoor recreation sport and leisure participation. Furthermore, it locates UK outdoor policy and strategy developments alongside wider sociological theoretical understanding of outdoor and alternative sporting activity use, choice and behaviour. By doing so we present a framework for understanding better the growth in outdoor recreation sport and leisure participation growth in the UK and beyond. Finally, the paper considers the implications of the growth of the UK outdoor recreation sport and leisure management sector.

The appropriation of outdoor recreation spaces for alternative formats of traditional running, wild swimming, and other competitive club-centred sports offer a useful case study for considering why governments and other agencies are attempting to employ them to address wide-ranging issues in the UK and beyond. This paper is an attempt to stimulate a new research agenda, shape future understanding and provide a starting point for the sport development industry to examine why, how and in what ways growth is occurring. It provides a new model, to begin to explore the diverse, complex and multi-tiered layers of the sector. The geographical focus of the paper is predominantly the UK context and the management and implementation of outdoor recreation in this setting. However, it is also hoped that given the potential application of growth in global outdoor recreation (OIA, 2019) and diverse geographical interests of the sector, it may also have wider application in other international sport and leisure management contexts.

It will also consider how this area of sport and leisure management is conceptualised by practitioners and academics. To help scholars, managers and government policy makers in this area we propose a new framework for beginning to understand the growth of this area based on a narrative review of the literature, several years of working in policy advocacy and as a collective of authors working across academia, practice and policy. 
The challenge with some of the emergent outdoor activities in the last decade such as open water swimming, obstacle courses, geo-caching and hybrid forms of 'traditional' recreation formats (for example 'challenge' events involving canoeing, mountaineering, cycling and rafting) is that they do not neatly fall within clear categories of sport, recreation or existing typologies of government and national governing bodies (NGBs). Indeed, they may well 'fit' no typology, dualistic traditional-alternative, outdoor-indoor or new-traditional binary theorisation. In some ways, they do 'fit' better with being considered 'alternative', in the physical context of taking place in the open spaces and places of the great outdoors (Hindley, 2018).

It is clear that socially constructed 'traditional outdoor recreation' sport and physical activity is worth acknowledging here. In terms of the kayaking, canoeing, walking, mountaineering, cycling and rock climbing mainstream activities significant numbers of participants now 'do this'. The consumption of such sports is captured in the table below taken from a specifically run set of statistics as part of the Reconomics project using the former Active People survey in 2014. This is the most comprehensive set of statistics government have 'run' from their ten year Active People Survey (2005-2015). These statistics were 'run' by the research team at Sport England, and were for the first time broken down into the smaller activities that are not representative due to very small numbers. However, it does give a sense of the breadth of what we might see from outdoor recreation. Note, however, how it is also hard to 'categorise' events such as open water swim, forest night running groups and obstacle and multiple format events (swim, raft, team challenge formats).

\begin{tabular}{|l|l|l|}
\hline Activity & $\begin{array}{l}\text { Number of people (14+) } \\
\text { participating monthly }\end{array}$ & $\begin{array}{l}\text { Percentage of the adult } \\
\text { population (14+) }\end{array}$ \\
\hline Outdoor Recreation Group** & $25,703,100$ & 59.3 \\
\hline Recreational walking & $23,313,500$ & 53.8 \\
\hline Outdoor Recreation Group (excluding walking) & $7,707,500$ & 17.8 \\
\hline Cycling & $3,524,400$ & 8.1 \\
\hline Running & $2,791,500$ & 6.3 \\
\hline Recreational cycling & $2,159,800$ & 5 \\
\hline Outdoor swimming & 826,700 & 1.9 \\
\hline
\end{tabular}




\begin{tabular}{|l|l|l|}
\hline Mountain biking & 736,900 & 1.7 \\
\hline Coarse fishing & 632,800 & 1.4 \\
\hline Other horse riding & 301,700 & 0.7 \\
\hline Sea fishing & 245,900 & 0.6 \\
\hline Outdoor climbing/trekking & 191,200 & 0.4 \\
\hline Game fishing & 155,800 & 0.4 \\
\hline Canoeing & 133,300 & 0.3 \\
\hline Alpine skiing & 95,900 & 0.2 \\
\hline BMX & 54,000 & 0.1 \\
\hline Cruising sailing & 47,600 & 0.1 \\
\hline Water-based rowing & 47,500 & 0.1 \\
\hline Pony trekking & 35,300 & 0.1 \\
\hline Snowboarding & 29,100 & 0.1 \\
\hline Cycle-Cross & 27,300 & 0.1 \\
\hline Freestyle skiing & 22,300 & 0.1 \\
\hline Windsurfing & 19,400 & 0.03 \\
\hline Nordic skiing & 17,400 & $\mathbf{1 0 0}$ \\
\hline Orienteering & $\mathbf{6 8 , 8 3 1 , 7 0 0}$ & 0.1 \\
\hline TOTAL & & \\
\hline
\end{tabular}

Table 1: Average monthly participation in sport and recreation in England*, October 2012-October 2013 (Source: Sport England, 2014, Active People Survey)

* at least 1 session, any duration, any intensity in last 28 days (October 2012-October 2013).

** The activities listed under the outdoor recreation group represent those from within the group that can be reported individually. It is not an extensive list of what is included in the APS.

Early identification and academic study of alternative sporting activities is often credited to the work of Nancy Midol (Midol 1993). Midol and Broyer (1995: 210) suggest that for such activities, "the culture is extremely different from the official one promoted by sporting institutions... These groups have dared to practice transgressive behaviours and create new values." Examples of research in this broad field has explored the practices of participants in 
Parkour (Atkinson, 2009; Camoletto et al, 2015; Puddle et al, 2018) and Ultimate Frisbee (Griggs, 2009ab. 2011; Crocket, 2013, 2016). Findings of what are sometimes called 'alternative sports' or events suggest that they present a challenge to the traditional way of doing and understanding sport and physical activity (Wheaton, 2000, 2004) and strongly adhere to practices which foster a close and supportive ethos (Bale, 1994; Eichberg, 1998; Rinehart and Sydnor, 2012). To date, this realm of the literature has not been positioned alongside that of outdoor recreation and management. We consider this a useful step in better conceptualising this 'market' and set of related management practices and emergent area of policy.

A specific example of such growth in an activity, which has soared in popularity in the UK in just a few short years, is that of obstacle course challenges. Events labelled Tough Mudder, Warrior Dash, Spartan Race, Rat Race, Wolf Run and Mucky Races have drawn hundreds of thousands of participants to stagger through mud troughs, crawl under barbed wire, scale high walls and attempt to swim across pits filled with ice cold water. Globally, since 2010 the Tough Mudder series alone has gone from just three races worldwide to over fifty, spanning USA, Australia and Western Europe and grossing over \$100 million dollars (Fitzpatrick, 2013; Martin 2013). The origins of obstacle races can be backdated to the Tough Guy challenge in England, first staged in 1987, originally billed as the toughest race in the world (Triggs, 2008). Organisers of such events attribute their use of social media as the primary catalyst for the industry's contemporary unprecedented growth and the considerable uptake of participants. Initial development of such pursuits obviously occurred pre-internet era. In a recent interview Michael Mendenhall, head of marketing at Walt Disney, credited with the building the X Games explains that "social media has allowed an idea like this to be adopted at a speed and scale we've never seen before...It used to take a decade or longer for something like this to take hold. Now you can do it in less than two years" (Kennedy, 2012). Such activities exist largely outside the domain of traditional government department, quasi-non-governmental organisation (QUANGO) and NGB jurisdiction.

However, for such ideas to take hold and develop the socio cultural conditions must also be right for events to develop at such a rapid rate. Insights have yet to be offered as to why this shift within movement culture has occurred. The paper will briefly, outline the emergence of outdoor recreation as a policy field within UK sport policy and management, secondly, it offers a new theoretical framework to help provide better explanation, understanding and management of this sport and leisure phenomenon. Finally, it considers the implications for 
the management and policy implementation of outdoor recreation as a growing agenda within government in the United Kingdom and in the wider global context.

\section{Background UK policy context}

Defining the outdoors is challenging, complex and problematic making it difficult to define clear boundaries for a sphere of public life, a professional industry and to estimate its economic, social and cultural value. As such the definition and conceptualisation of outdoor recreation is always evolving. Natural England's outdoor recreation strategy (Henley Centre, 2005) highlighted that a concise definition of outdoor recreation is difficult to establish as it includes many different activities. 
In this paper, we take outdoor recreation to mean physical activities which take place in the natural environment. Furthermore, our definition of the natural environment does not include outdoor pitches, which can be considered purpose-built, and as such, our definition does not incorporate sports such as football, rugby or golf. We recognise that some of the activities included within our definition can take place in purpose-built settings, for example canoeing, skiing and climbing. However, we consider these as having their roots in the outdoor recreation and predominantly reliant on the natural environment - therefore in keeping with our definition. This definition itself was an agreed one formed through several rounds of consultation that formed part of the development of the Reconomics (2014) report by the Sport and Recreation Alliance (SRA) members from over 320 organisations. This process itself was a first for the industry as an attempt to build a definitional consensus and identity as part of moving forward as a collective of organisations with vested interests. Activities that we have included within this definition, as determined by this consultation process were categorised according to the natural environment in which they take place (Figure 1). This is illustrated in Figure 1 with a categorisation taxonomy across the six environmental contexts that emerged through the SRA consultation.

Figure 1: Typology of outdoor recreation based on the natural environment in which they take place.

UNDERGROUND

eg caving and potholing
IN WATER

eg outdoor swimming, scuba diving

\section{ON WATER}

eg angling, canoeing, waterskiing 
eg walking, horse-riding, off- eg mountain climbing, high eg gliding, sky diving road cycling ropes

Source: Reconomics, Sport and Recreation Alliance (2014)

Given the close link between the identified benefits of outdoor recreation and the outcomes sought internationally by governments the increased focus on the potential of outdoor recreation as a policy tool has become evident in the last 15 years (DEFRA, 2017). More detail will be provided later in this paper around the identified benefits of outdoor recreation. Dating back now to its first publication in 2002, the UK's Governments Game Plan strategy for sport (Cabinet Office and DCMS, 2002) did not specifically mention outdoor recreation. In the UK, sport policy is driven by DCMS and the delivered by Sport England and many national partners such as County Sport Partnerships (CSPs), NGBs, local government and charity and social enterprise sector. This is not excluding the sizeable voluntary sector who 'do' much of policy in this sector where much of the outdoor recreation sector sits. For a fuller explanation of the UK sport development system of relevance to outdoor recreation see Cutforth (2017).

Equally, outdoor recreation is a cross cutting sub-sector of sport and physical activity policy that can equally embrace agencies as diverse as National Parks, the Forestry Commission, The National Trust, Natural England and sub-sector specific leisure providers working with more traditional policy makers such as Sport England and DCMS. Again, space does not permit a full outline of the historical map of these agencies and their inter-relationships in this paper.

It is worth acknowledging a little known document led by Natural England who did produce an outdoor recreation strategy (Countryside Agency, 2005). This strategy highlighted the potential variety of categories of outdoor recreational activities that make the interpretation of this sphere of sport and active recreation particularly complex. It is then thirteen years after the previous government sport strategy Game Plan (Cabinet Office/DCMS, 2002), that the latest incarnation Sporting Future (DCMS, 2015) specifically identified outdoor recreation as an asset in the effort to increase levels of physical activity. Within this latest strategy acknowledgement is given to the value that outdoor recreation contributes to the economy, and identified actions to improve monitoring of engagement in outdoor recreation and better understand behaviours. This alone was a significant policy landmark. But, policy also went 
beyond sport, to consider physical activity (bringing many forms of outdoor recreation within its remit) and also moving beyond a purely participation focused definition of success. Instead, Sporting Future defines five outcomes by which success will be measured: physical wellbeing, mental wellbeing, individual development, social and community development and economic development. These outcomes are reflected in Sport England's Toward an Active Nation strategy (Sport England, 2016a). Here, Toward an Active Nation recognises the potential of outdoor recreation to help achieve those targets, and, also sets an "increase in the percentage of adults using outdoor space for exercise/health reasons" as one of its KPIs" (p 25).

It is also worth being aware of wider policy agenda development and advocacy work that underpinned this emerging strategy. For example, the publication of Reconomics: The Economic Impact of Outdoor Recreation in the UK - The Evidence (Comley and Mackintosh, 2014) was led by the Sport and Recreation Alliance (known brand-wise hereon within this paper as 'The Alliance') and was used in a House of Parliament debate (UK Parliament, 2015) to underpin and encourage a wider DCMS consultation in August 2015 on a potential Outdoor Recreation Strategy for the United Kingdom. DCMS asked the Alliance and Outdoor Industries Association (OIA) to consult with the outdoor recreation sector on what could be included in a national outdoor recreation strategy for England. Given that participation, physical activity development and promotion are core to this strategy consultation (DCMS, 2015a) it is surprising that previous government policy has not highlighted the role of outdoor recreation within sport development (Cabinet Office/DCMS, 2002). The presence of outdoor recreation within national policy is partly the product of such advocacy and the coalescing of various interest groups including The Alliance, outdoor recreation NGBs, the OIA and wider outdoor sector parties. The Alliance is the umbrella organisation for the sport and recreation sector in the UK with over 330 members including national governing bodies and other representative bodies. Established in 1935 and originally named the Central Council of Physical Recreation, the Alliance exists to protect, promote and provide for its members. Between them the Alliance members represent some 150,000 clubs and eight million regular participants.

Precise definition of this policy area is difficult, political by nature and driven by multiple vested interests. However, as part of the Reconomics policy advocacy and lobbying process (Sport and Recreation Alliance, 2014; Comley and Mackintosh, 2014) a series of debates in Parliament were generated (UK Parliament, 2015, Sport and Recreation Alliance, 2017). Within this set of debates a fairly traditional framework was proposed for setting boundaries 
around what was, and what was not outdoor recreation. This drawing of policy limits is critical to understand, but also to manage policy in this area. But, as this article shows further wider review of the conceptual sociological literature in this domain illustrates that such an overtly 'tight', concrete and formalised set of named activities that fall within the sector is hard to delineate.

Furthermore, in the spirit of UK-wide, cross-government working, consideration of increased physical activity and outdoor recreation has not been limited to the sport strategy. Public Health England's Everybody Active, Every Day report (2014) aimed at tackling the estimated $£ 7.4$ Billion annual cost of physical inactivity identifies the benefit of improving ease of access to open space. Likewise, the government's 25 year Department of the Environment Forestry and Rural Affairs (DEFRA) environment plan contains an entire chapter on "connecting people with the environment to improve health and wellbeing" (2018). To assist in achieving all of this, Natural England's "Outdoors for All" programme is aimed at increasing access to the natural environment for people in England. It appears there is now a much greater awareness and appreciation of the benefits outdoor recreation can offer, and as a result outdoor recreation receives prominent consideration in government strategies to increase participation in physical activity and improve health and wellbeing across England. But, what remains is a need to better understand the levers, drivers and conceptual literature that potentially underpins this fast emerging policy domain.

\section{Theoretical explanation of shift towards outdoor recreation}

For the past seven years we have been engaged in this area of policy making, review and research (SRA, 2014; SRA 2017) as well as open debate in Parliament (UK Parliament, 2015). This seven year process has involved undertaking multiple literature reviews, running consultation events with policy makers and engaging with stakeholders in wider outdoor recreation. Ontologically, we position ourselves as social constructivist policy interpretivist analysts (Bevir and Rhodes, 2010; 2011; 2018; Wagennar, 2011). Epistemologically, this means we undertake such reflexivity in our research with an openness and awareness of how we ourselves are part of the process, part driving the processes of policy. But, in offering a framework this offers a tool kit for understanding wider literature, projects, industry documents and policy offers. It also allows us as researchers to reflect upon why outdoor recreation, of all policy 'fields' is used, shaped and re-shaped to deliver outcomes for government. We believe 
it is partly, but never wholly driven by some of these five driving factors. These five factors emerge in part from our 'practice', praxis and theoretical understanding in this area. But also from the narrative literature review undertaken in this area. Importantly, we aim to reduce the binary divide between higher education and industry and theory and practice (Best, 2009; Mackintosh, 2018). In each of the next sections we illustrate five aspects of our new theoretical framework we propose for the growth in outdoor recreation as an alternative leisure phenomenon. Figure 2 below illustrates this framework that we hope will stimulate debate, a new research agenda and provide a starting point for examining the great outdoors and its role within sport development and sport policy implementation and evaluation. The diagram is meant as a starting point for providing a theoretical framework for understanding the growth in outdoor recreation with each of the five components being considered drivers in the societal and industry growth. There are naturally also conceptual links between these five components too.

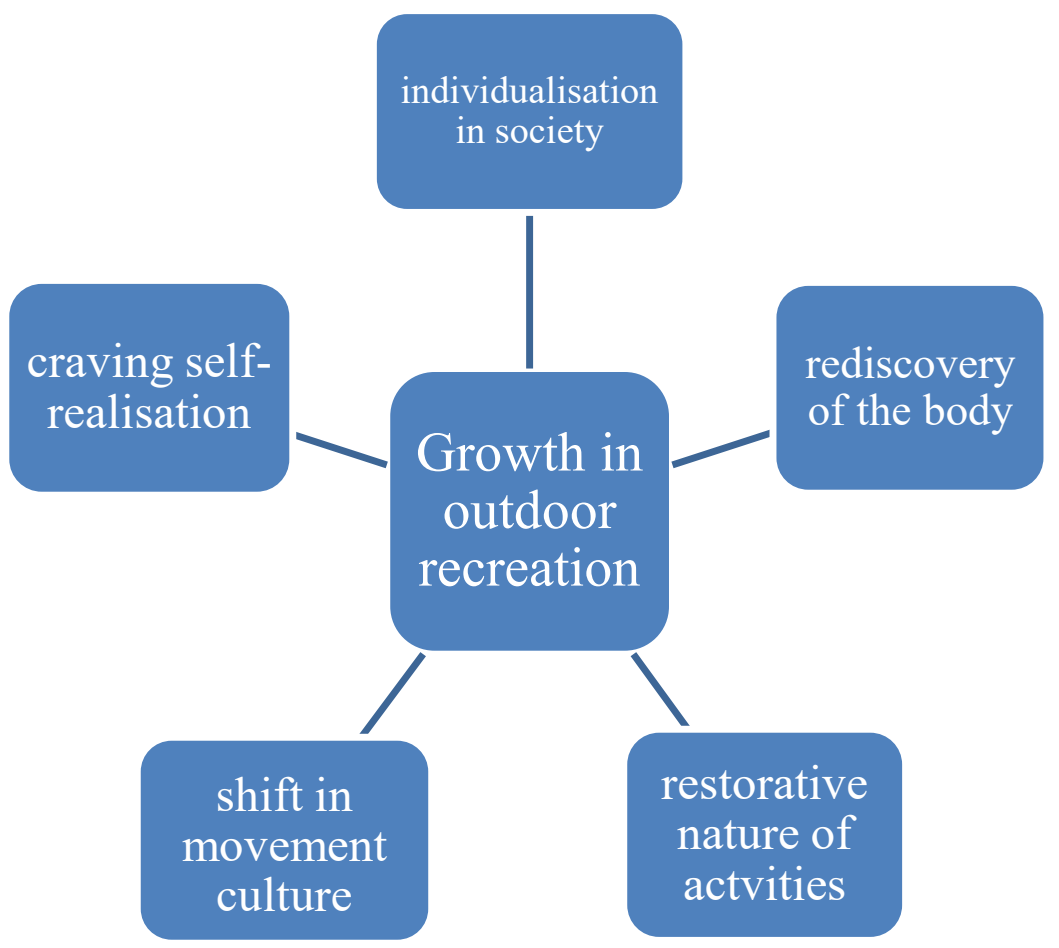

Figure 2: A framework for understanding the growth in outdoor recreation 


\section{Restorative nature of outdoor recreation}

Use of green and blue spaces for physical activity, movement and sport is not new. However, with growing use of this area of policy by the UK government (DEFRA, 2018; DCMS; 2015; Sport England, 2016) it seems that greater attention is needed as to why people are seeking alternatives to the indoor club, gym space or the more traditional sporting endeavour. One area in the literature that appears to be prevalent is the notion of the outdoors as possessing restorative value. Green exercise differs from indoor exercise in several ways, including the idea of nature as an escape from everyday life (Gladwell et. al., 2013), and as a provider of restoration (e.g. from mental fatigue; Herzog et. al., 1997, Hertzog et al 2002, Hertzog and Strevey 2008; Ojala et al, 2018). It is perhaps more enjoyable and easier too, for many participants. Some studies have shown that exercising in the outdoors feels easier to participants than if they were to perform the same exercise indoors (Focht, 2009), possibly because of the diverting and attractive features of a green setting (Akers et. al., 2012) and the idea of nature-based recreation as escape and refreshment (Morris, 2003; Ojala et al, 2018).

Exercising in nature also mediates the frequency with which participants choose to engage in exercise, with the restorative properties of nature cited as a reason for more frequent participation (Bowler et. al., 2010) alongside improvements in mood (Peacock et. al., 2007, Barton \& Pretty, 2010, Bratman et al, 2015; Pretty et. al., 2005; ten Brink et al, 2016). Interestingly, the greatest improvements on mood and self-esteem appear to emerge in the first 5 minutes of green and blue exercise (Barton \& Pretty, 2010), with long and short term benefits observed (Gladwell et. Al., 2013) with exposure to green exercise for short periods. Conversely, a failure to engage with nature on any level (e.g. a child living on an inner-city estate) has been named 'nature deficit disorder' (Louv, 2005) leading to an upswing in the potential for greater levels of stress, anxiety, depression and other mood disturbances (alongside obesity) to occur.

The role of green exercise (exercising whilst being exposed to nature) in health is significant (Park et. Al., 2010; Barton \& Pretty, 2010; Barton, Griffin \& Pretty, 2012; Gidlow et al, 2016), with natural environments providing a means of relaxation and reducing stress as a natural byproduct of the experience ( $\mathrm{Li}, 2010)$. According to a recent systematic review, it also offers 
more mental benefits than indoor exercise (Thompson et. al., 2011). Furthermore, it has been identified that,

'natural settings and stimuli such as landscapes and animals seem to effortlessly engage our attention, allowing us to attend without paying attention.'

(Kuo \& Sullivan, 2001, p. 545).

Research identifies the restorative role of nature (Gladwell et. al., 2013; Herzog et. al., 2003, 2008; Kaplan \& Kaplan, 1989), with outdoor exercise referred to as a 'useful natural medicine' (Gladwell et. al., 2013, p. 5) that promotes happiness (Sugiyama et. al., 2008), which carries the potential to provide positive emotional regulation (Korpela \& Ylén, 2009), to alleviate stress, and allow emotional stress-recovery to occur (Bowler, Buyung-Ali, Knight \& Pullin, 2010; Korpela, 2014), partly via the use of rehabilitative intervention programmes such as gardening on depressed patients (e.g. Gonzalez et. al., 2011). A meta-analysis (Bowler et. al., 2010) comparing urban and natural environments reported that the strongest restorative outcome of nature-based exercise was well-being, and a decrease in negative feelings such as sadness and anxiety. This supported the findings of previous research that also found greater positive changes in a wide range of behaviours associated with emotional well-being following nature-based (as opposed to non-nature-based) exercise (Berman, Jonides \& Kaplan, 2008, Korpela et. al., 2014; Gidlow et al, 2016; Ryan et. al., 2010,). These findings reflect a growth in interest in the field of environmental psychology, which adopts 'restoration perspectives' on the use of nature in restoring mental, physical and emotional health.

The restorative properties for urban dwellers appears striking if one considers a rather seminal body of work conducted by Ulrich (e.g. 1979, 1981, 1984, 1991, 2002) who considers that the viewing of natural blue and green scenes goes far beyond an aesthetic appreciation to concrete improvements in stress and emotional well-being. Interestingly, many authors discuss that nature-based scenes carry such a strong psychological impact that simply viewing photographs of nature can alleviate stress (e.g. Morris, 2003; Ulrich, 1984, Kaplan, 1992, Ulrich \& Parsons, 1992, White \& Heerwagen, 1998). As observed by Korpela et. al. (2014), walking in the outdoors, as opposed to indoors, 'produces greater physiological changes toward relaxation, greater changes to positive emotions and vitality, and faster recovery of attention-demanding cognitive performances' (Korpela et. al, 2014, p. 2). In fact, it is perhaps restoration, as opposed 
to exercise itself that provides the greatest benefits of outdoor exercise. As stated by Korpela et. Al., (2014), p. 5),

\begin{abstract}
'the present result refers to the importance of experiencing everyday calmness, getting new spirit and vitality for the everyday routines, forgetting everyday worries, clarifying one's thoughts' and signifies the importance of moving 'away from physical exercise per se in population groups who are inactive or insensitive to exercise prescriptions' (p. 5).
\end{abstract}

Such an observation holds with conceptualisations of outdoor-exercisers as 'recreationists' for whom the experience of being outdoors dominates. Outdoor exercisers can benefit from exercise, whilst also relaxing in nature, enjoying the aesthetic beauty of their surroundings, and partaking of the physical benefits such as fresh air and an escape from everyday life (Barton et. al., 2009, Hammitt, 2000). From considering how this international body of literature is framing outdoor recreation leads into a consideration of how 'movement culture' per se has grown in what has been referred to as an era of second modernity. The next section will consider how and why such a wider culture has developed. 


\section{A shift in UK movement culture towards second modernity}

Movement cultures within any country are rich and varied containing patterns of movement actions and interactions (sport, play, dance, or other fitness activities) that encompass a group's leisure (Crum, 1993). "Within the UK movement culture, 'sport' has occupied a dominant position, traditionally conceived of as highly competitive in which the achievement motive has remained dominant (Griggs, 2012: 180). Historically the creation and maintenance of competitive sports clubs have done much to reinforce position this with the formation of league and cup contests. These developed exponentially during the Victorian era from well-established organisational structures of civil clubs founded largely around factories and churches (Walvin, 1975). Since the dominance of sport was established the broader cultural landscape has continued to shift and consequently "the movement-cultural landscape has drastically changed" (Crum, 1994: 118). In contrast to this it has been suggested that 'outdoor recreation and, in particular, walking is a multi-sensual and stimulating experience which frees the mind and generates reflexivity, philosophical and intellectual thought, aesthetic contemplation and opens up a more 'natural' self' (Morris, 2003, p. 18).

Beck (2011) explains the wider societal shift as a move from first modernity to that of second modernity (see also Beck et al, 2003). In first modernity the freedom and equality of its individuals are moulded by powerful social institutions to which they are strongly adhered and disciplined by such as the work place, school and the church (Beck et al, 2003). By contrast in second modernity, society is far more globalised exacerbated by developments in technology. In addition tradition patterns of family life, gender roles and working practices have also occurred (Beck and Beck-Gernsheim, 1995). With first modernity more reflective of societal needs and survival, second modernity has allowed considerable freedoms for more recent generations, raising 'children of an excitement society' (Shulze, 1992). This period has seen more intense individualisation has also developed a more consumerist and choice driven society which sees less legitimacy in traditional social institutions and has thus eroded many traditional prescriptive life patterns (Beck and Beck-Gernsheim, 2001). Beck (2011:281) concludes that this leaves us with "a new kind of society and a new kind of personal life [that] are coming into being."

This new kind of personal life is reflected in the move to participate in alternative sporting activities such as parkour, Ultimate Frisbee and obstacle course challenges which have begun 
to be documented in sporting ethnographies (Rinehart and Sydnor, 2012; Wheaton, 2004 Puddle, Wheaton and Thorpe, 2018). In his analysis of a shift in movement culture and building upon the idea of what is referred to as a shift in post materialist values, Crum (1993) offers three further aspects to explain its change namely, the craving for self-realisation, the trend towards individualisation and the rediscovery of the body through the outdoors. Though outlined by Crum however, these societal shifts remain largely unexplored and may offer some explanations as to why outdoor recreation potentially offer such a popular sport policy solution. These themes will now be discussed in turn.

\section{The craving for self-realisation}

First modernity was characterised by more rigid notions of authority and morality and identity (Giddens, 1991). By contrast second modernity has created "new patterns of family life, marriage and divorce, labour market participation, work and global economy" (Prout, 2000: 306). It has become epitomised by greater uncertainty (Beck, 1992;) but this uncertain climate has proved to be fertile conditions in which people can shape their own lives through the formation and exercise of self-consciousness, creativity and agency (Griggs, 2013; Prout, 2000). Within Western societies, which have enjoyed increased leisure time and money this has led to populations being irresistibly drawn along a path of self-realisation as they engage in an ever evolving range of pursuits which have developed of which obstacle course challenges are one such example (Lubbe. 1988). As consumption has increased the leisure choices that people make increasingly serve as a source of identity (Rinehart and Sydnor, 2012; Wheaton, 2004; Puddle, Wheaton and Thorpe, 2018). Crum (1994) suggests that sport is the clearest illustration of this. "In modern societies there is no cultural domain which is more accessible as a medium for the experience and training of self-determination and selfrealisation for so many people, irrespective of their sex, age, social class and level of education" (Crum, 1994: 119). However while there may well be increased participation within the broader movement culture there continues a direction away from convention and regulation (Griggs, 2013). Research suggests that the draw of participating in more alternative physical activities lies within their underpinning philosophies of encouraging self-expression and personal growth (Midol and Broyer, 1995; Rinehart and Sydnor, 2012). A further common feature is participants ongoing search for authentic experiences (Butts, 2001; Wheaton, 2000). 
Nettleton, and Hardey (2006) suggest that running events such as outdoor trail events, fun runs, marathons, obstacle course races are considered extraordinary among the routine lives of runners and within these events Shipway, Holloway and Jones (2013) reports an abundance of authentically felt experiences. What might be best termed existential authenticity, sees participants engaging in a freer, less constrained social environment in search of their true self. as a counter dose to the loss of true self ${ }^{\mathrm{ee}}$ in public roles and public spheres ${ }^{\text {ee }}$ (Wang,1999: 358). Though it has long been known that distance running challenges are about managing experiences and feelings of pleasure and pain (Bale, 2004) these have long been the preserve of the committed and regular runner. The creation of events such as obstacle course challenges has opened up the potential experiences to wider groups of people. Importantly these events provide a dual motivational appeal, allowing some to focus on pushing oneself to a prescribed limit and allowing other simply to face and overcome new challenges against the backdrop of a cheering crowd or a scenic route (Shipway and Jones, 2010).

Motivation in physical activity is popularly attributed to achievement goal theory where the primary motive is for learning, striving, and the desire to demonstrate competence (Roberts et al, 2007). Individuals are said to be motivated by task, whereby individuals find success in working hard and improving or by performance by better compared to others or prescribed standards (Hagger and Chatzisarantis, 2005). Mullins (2012) indicates that these two perspectives are prevalent among core groups of obstacle race participants. Furthermore from a psychologically perspective, obstacle course participation meets the three powerful needs of self-determination theory; acting with autonomy, developing competence and feeling socially connected (Caron et al, 2003; Kilpatrick et al, 2002). Uniquely perhaps obstacle course races provide entrants the ability to choose to compete to win, to be challenged or participate for fun, offer autonomy for a broad range of people in an environment where they can develop their own skills and assist others in need (Mullins, 2012). Derom and Yeks (2011) suggest that use of marketing of obstacle course challenges, particularly through the use of social media has been focused across these differing psychological needs, appealing to the craving we appear to have for self-realisation within second modernity. The use of social media and our creation of identity within is also reflective a trend towards individualisation, a theme to which we move next. 


\section{The trend towards individualisation}

In first modernity traditional collective organisations such as the church and labour unions were of major significance to many and commanded significant power (Giddens, 1990, 1991). This power was also reflected in significant role played by civil groups such as sports clubs (Lubbe, 1998). However in second modernity, rather than choosing to be seen to have prescribed or standard identities through memberships and affiliations there is an unabated trend towards people coming to think of themselves as unique individuals (Prout, 2000). Among young people Beck (1998: 78) suggests that within Western Cultures this concept of individualisation is so strong that they "...no longer become individualized. They individualize themselves. The 'biographization' of youth means becoming active, struggling and designing one's own life (Beck, 1998: 78). The values espoused by traditional sporting forms represent the antithesis of this viewpoint. Holland and Thomson (1999) indicate that the prevailing attitude on the part of young people in empirical findings thrives in new kinds of institutions in which authority, and allegiance, must be constantly renegotiated, re-established and earned. In short, in an increasingly individualised world, young people articulate an "ethic of reciprocity arguing that their respect could be won by anyone who respected them . . . they tend to be very wary of claims to authority and respect on the basis of tradition, custom or force (Prout, 2000: 308).

Consequently, it is argued identity is now more fragmented (Giddens 1991; Mort, 1988). As such, fragmented discourses around identity construction offer the opportunity for the development and establishment of more varied identities, shaped increasingly away from those produced around work and career (Jackson et al. 2001, Whannel, 2002) and more around leisure choices (Featherstone, 1991). Wheaton (2004) suggests that participation in alternative physical activities represent opportunities for people to live out these individualised identities. Findings from Shipway and Holloway (2010) suggest that extraordinary running events such as outdoor obstacle course challenges are ideal vehicles for individual identity reinforcement. This is because running success is immediately recognisable and can be understood, where the standards of achievement can be seen by participants, family, work colleagues and other audiences. Again perhaps similar could be seen in wild swimming events, trail adventure and those seeking what we refer to earlier as the 'restorative effects' of green or blue leisure. Excellence in physical performance is typically admired as is effort, especially when participants are new to running or participate for good causes (Derom and Yeks, 2011). It appears that distance running events appear to have the ability to attract participants of both 
serious leisure (Stebbins, 1992) and casual leisure (Stebbins, 1997). Previously longer distances had been prohibitive either by application or by the level of training needed. Both $5 \mathrm{~km}$ and $10 \mathrm{~km}$ races had also gained popularity but had largely catered for running clubs and focused on achieved times. However obstacle course challenges have successfully made these environments open to all (Shipway and Holloway, 2010). The broader rise in popularity of similar events is also indicative of the next theme, the rediscovery of the body.

\section{The rediscovery of the body}

A negative aspect attributed to a move to a more individualised culture there is the rising incidence of reported mental health problems among young people. Rutter and Smith (1995: 807 ) indicate unequivocally that "...the shift towards individualistic values, the increasing emphasis on self-realisation and fulfilment, and the consequent rise in expectations, should be studied as possible causes of disorders." The shift to second modernity has seen changes in our daily routines as we have moved to greater sedentary office based work practices and embraced the development of modern technologies. Consequently, our bodies have reflected this shift of 'movement denial' by exhibiting increased stress and cardio vascular illnesses (WHF, 2011).

At the same time, the growth of the fitness industry and a trend towards health and wellbeing practices is illustrative of something of a 'rediscovery of the body' (Bette, 1989). Despite accepting the sedentary lifestyle that we have created, we also appear to have a deep need to escape these shackles and engage in liberating behaviour, termed by sociologists Elias and Dunning (1986) as a quest for excitement. Illustrative of this phenomena are examples of highly respected white collar workers such accountants, lawyers, bankers and doctors who feel constrained by their office environments, engaging in violent and illegal behaviour by engaging in acts of football hooliganism at the weekend (Giulianotti, 1995). Thus engaging in obstacle course challenges would provide what has also been termed by psychologists as sensation seeking behaviour, which sees individuals participation in experiences which are varied, novel, complex, and intense (Zuckerman, 1983). While physical activity literature has often historically associated these behaviours with high-risk sports (Breivik, 1996; Rossi and Cereatti, 1993), Zuckerman (1994) suggests that individuals can still pursue personally intense and rewarding sensations without seeking extreme risks for their own sake.

Benefits can also be found for the more serious or dedicated athlete. Typically, training schedules are prescribed and largely uniform so the varied terrain can provide a form of interval 
training that can enhance both aerobic and anaerobic capacities (Cramer, 2008; Reuter and Hagerman, 2008). A more forgiving terrain can also soften regular high impact training and the movement diversity also distributes training stress over more muscles and joints, which may reduce risks of overuse injuries (Auvinen, 2008). This diversity of movement activities can also break the monotony of repetitive training schedules (Laursen, 2010).

The more recent importance of positive socio-affective environments during physical activity is also reflective of a more holistic view of health and wellbeing beyond the psychomotor domain (Rink, 2005). Empirical findings indicate that strong social bonds developed through a shared ethos common in alternative physical activities appear to create highly desirable environments for increased and sustained participation (Stebbins, 1992; Wheaton, 2007). This is reflective of the accounts obtained during obstacle course challenges (Mullins, 2012) and of other events that provide participants with a powerful sense of identity, community and belonging (Shipway and Jones, 2008).

\section{Discussion}

In this paper we propose five key drivers that together build a new framework to help partially explain the growth in outdoor recreation as a tool, instrument and most malleable of policy vehicle for government. We also want to reposition the need to consider involvement of the policy researcher and advocate within the research process for enabling a reflexive account of how policy and practice is understood (Wagennar, 2011). Indeed, the missing voices from this paper are those of the lobbyists, activists, club volunteers, participants and consumers of outdoor recreation, in its many multiple forms at different hierarchical levels in society. We suggest this is a future avenue of sport and leisure management research yet to be fully explored. In classifying, conceptualising and defining outdoor recreation we assume this in itself is a socially constructed process. Policy analysis of this sector is missing. Understanding why certain activities do and don't get funding is an increasingly crucially research agenda. Furthermore, our framework can only provide a partially constructed point of reference for understanding growth in a fluid domain of leisure and sport.

By better understanding this area of activities, management and policy interventions, managers, volunteers and communities can better plan, cooperate and innovate to build a more cohesive responsive to government policy language, strategies and funding (DCMS, 2015; Sport 
England, 2016). The artificial spectrum of outdoor activities proposed by The Alliance (SRA, 2014) used in government outdoor recreation policy debates (UK Parliament, 2015) went on to frame government policy formulation (DCMS, 2015; Sport England 2016). For the first time in DCMS sport policy outdoor recreation had an acknowledged role to play. This opens doors for a diversity of agencies, communities groups, social enterprises and charities to access funds, support and strategy agendas. Similarly, it remains clear that whether a private profit-driven Tough Mudder event, inner city dockland 'Open Water Swim' activity run by the English swimming NGB or a micro-level community walking group, the boundaries, definition and liminal spaces of this policy field are increasingly complex. How we navigate at a national level an increasingly expansionary area of provision is where we must next build a clearer research agenda. The Alliance has a key role to play here, but also the far wider policy community too. This sector encompasses diverse partners such as the National Trust, The National Parks, local government parks and open spaces departments, NGBs and the ever more important collective 'patchwork' of non-traditional providers. In hard economic terms, it seems we have a better feel for supply side agencies and those who deliver and where they deliver. But, this paper maps the ever nuanced demand side factors that suggest why it may be that outdoor recreation is growing. In a period of second modernity, we suggest that it perhaps through the five key drivers that we identify that we can better grasp why it is growing.

In addition, it has been clearly recognised that government has failed to meet the long heralded expectations of the London 2012 participation boom (Mackintosh, Darko and May-Wilkins, 2015). Likewise, that the multiple agencies that are being asked to respond to this much vaunted crisis need to be increasingly innovative and seek collaborations and partnerships beyond their usual policy and practice bedfellows. It is clear that one of the policy landscapes that is bucking the trend, is that of the outdoor recreation. It is clear that there is an artificial binary divide between traditional and alternative outdoor recreation. The last government strategy for sport suggested the impetus for Creating a Sporting Habit for Life (DCMS, 2015). We are now no longer aiming to reach out for a mass participation legacy driven by securing global megaevents. But, as we move into the next phase of austerity-led policy making for sport and physical activity it seems that the outdoor recreation market, potentially offers some of the opportunities that constrain other areas of policy and programme development such as social and healthcare, mental health provision, education provision and prisons (BBC, 2018; Meek, 2018). More recent work by the Sport and Recreation Alliance (2017) has outlined the potential of the outdoor recreation sector. What is less clear is whether other sports, and their NGBs have 
recognised this opportunity as one they could learn from and see how success can be defined differently to traditional notions of mainstream sport culture. For example, Active Forests and partnerships between the Forestry Commission and diverse sports such as table tennis, volleyball, Nordic walking, fitness, climbing, wild running, archery and duathlon (O'Brien and Forester, 2017). A further example of the outdoor recreational growth capacity is how it has been facilitated through green spaces in the global phenomenon of Park Run (Hindley, 2018; Stevinson and Hickson, 2014). The Active Forest and various Park Run evaluations show that we cannot make blanket assumptions of impact across settings, formats and adaptations of sport and physical activity in outdoor spaces. Research and researchers in sport and leisure management have a clear role to play (Mackintosh, 2018) in breaking down the artificial boundaries of 'evidence-based practice' and 'policy-based evidence' social constructs between Higher education and 'practice'. Earlier sections of this paper have also begun to map out debates around the motivations, meanings and beliefs that may underpin this new area of movement culture and physical activity.

\section{Conclusion}

A new collective research agenda and national policy leadership is needed in this little understood domain. Policy research in this area, despite the growth in participation, provision and policy rhetoric is incredibly rare. Indeed the policy actors, agencies and organisations in this area have no single 'national voice', or strategic vehicle for supporting each other and avoiding duplication of efforts. We consider it a fruitful and vital time for traditional and mainstream sports to learn from this sphere of activity that is thriving, to begin to reconceptualise what it is they want to achieve and how they can begin to affect the long held status quo in sport participation (Carter, 2005; Mackintosh, 2012; Mackintosh and Liddle, 2015; White and Houlihan, 2002).

The opportunities may be greatest for small governing bodies of sport that embrace and focus on the outdoor recreation landscape, but who can adapt traditional formats of their codes to embody new versions of the modern, hybrid and developmental that appeals to the wider market. This could for example be in activities as diverse as orienteering, cycling, rugby, where there is a branded and themed challenge, and extreme element to the game adapted to this event-led version of activities using the great outdoor spaces of the UK. For some NGBs this simply means using the open spaces, places and landscapes of the outdoors for accessing new 
audiences. Research into lifestyle sport is becoming increasingly well established (Wheaton, 2013), but, as more NGBs become increasingly centrally focussed on delivery of activities (Hylton, 2013) so the potential for learning and cross over is greater. We question whether lifestyle, alternative or traditional are useful terms anymore. For the users, consumers, community groups and managers or sport and leisure we perhaps need to return to the spaces and places that determine who plays, enjoys and takes part and consider why, when and how they do so in better planning leisure provision. Traditional NGBs have much to learn from organic and more culture-led minority and 'alternative' sports. Some have started to tackle this flow of engaging with learning such as table tennis launching PING! its outdoor street, bar and public space adaptation of an older format (Mackintosh, Griggs and Cookson, 2014). From an original pilot around the Olympic stadium this version of the event running mainly through summer months now has expanded to hundreds of tables in 19 UK cities (Table Tennis England, 2014) in parks, forests and outdoor recreation spaces. In parallel to this, event-based activities in cricket such as Cage Cricket show that even the most parochial of NGBs are starting to lean towards demand and engage with alternative formats (ECB, 2015).

Where this is a continued gap in academic and industry understanding is in understanding beliefs, motivations and participant behaviour centred on what others have referred to as at times a rather mystical latent demand for sport and physical activity (Bullough, 2012; Sport England, 2014). The shift to individualisation and craving for self-realisation through informality and the lack of regular commitment required with organised sports shows the potential of outdoor recreation for DCMS, Sport England and wider government (DEFRA, DoH and DCLG). It seems that we need to consider how individuals and group aspects linked to communities, families and friends illustrate how outdoor recreation facilitates the inclusion of boarder demographic groups in co-participation. For example, minority groups who access outdoor recreation less need to be better considered to identify what barriers sport and leisure providers and organisational infrastructure agencies put in place. Spaces and places for leisure then need to be proactively managed better to encompass such views using a research-led approach (Medcalf and Mackintosh, 2018). The scope with which factors including (but not limited to) gender, ethnicity, disability and social class shape or constrain growth of the outdoor recreation community are a critical line of future enquiry for policy makers and academic researchers. We encourage both communities of interested parties alongside those managing outdoor recreation practice to begin to examine these area beyond the 'gaze' and experience of the white middle class male. 
We have mapped out a framework that we propose that may underpin the development and in one specific alternative to this broader stagnant trend. Considering activities such as The Tough Mudder-type event has currently limited understanding. Yet we see this and other alternative incarnations that have begun to be more systematically developed, in part as a response to linking monitoring of NGB sport participation levels with potential reward of future funding. If Tough Mudder-style events and similar outdoor recreation alternatives are becoming a participation success globally, we need to question what is it about them that both funding agencies, sport development practitioners and policy makers can learn from. The natural link is to other events that run in other models of delivery such as Park Run (Hindley, 2018) and Active Forests partnership by Sport England (O'Brien and Forester, 2017). As sport and leisure managers, this, perhaps simply put, can allow us to better meet the needs of the individual participant and our communities. Future research needs to examine emergent new formats of activities that.

Inflexibility in funding based on existing tiers of decision makers in NGBs and a failure to open access to these new potential exciting markets as examined in this paper are currently limiting future expansion and growth. If craving for self-actualisation amidst an increasingly individualised leisure experience is how societies and communities are organising themselves then it is for the leisure and sport providers to respond to this challenge. Exploring the communities, individuals and policy makers that are part of this movement in the UK and beyond is both an empirical and theoretical challenge that can offer considerable insights for the management and development of sport and leisure.

\section{References}

Atkinson, M. (2009) Parkour, anarcho-environmentalism, and poiesis. Journal of sport and social issues, 33 (2), 169-194.

Akers, A., Barton, J., Cosey, R. Gainsford, P., Griffin, M., Mickelwright, D. (2012) Visual colour perception in green exercise: Positive effects on mood and perceived exertion. Environmental Science \& Technology, 46, 8661-6. 
Auvinen J, Tammelin T, Taimela S, Zitting P, Mutanen P, Karppinen J. (2008) Musculoskeletal pains in relation to different sport and exercise activities in youth. Medicine Science and Sports Exercise, 40, 1890-1900.

Bale, J. (1994) Landscapes of Modern Sport. Leicester: Leicester University Press.

Barton, J., Pretty, J. (2010) What is the best dose of nature and green exercise for improving mental health? A multi-study analysis. Environmental Science and Technology, 4, 3947-55.

Barton, J., Hine, R., Pretty, J. (2009) The health benefits of walking in greenspaces of high natural and heritage value. J. Integrated. Environmental Science, 6 (4), 1-18.

Barton, J., Griffin, M., Pretty, J. (2012) Exercise-, nature- and socially interactive-based initiatives improve mood and self-esteem in the clinical population, Perspectives in Public Health, 132, 89-96.

Beck U. (1992) Risk Society: Towards a New Modernity. London: Sage.

Beck, U. and Beck-Gernsheim, E. (1995) The Normal Chaos of Love. Cambridge: Polity Press.

Beck, U. and Beck-Gernsheim, E. (2001) Individualization. London: Sage.

Beck, U., Bonss, W., and Lau, C. (2003) The Theory of Reflexive Modernization: Problematic, Hypotheses and Research Programme, Theory Culture Society, 20 (2) 1 - 33.

Beck, U. (2011) The Cosmopolitan Manifesto, In D. Held and G. Brown (eds) The Cosmopolitanism Reader. Cambridge: Polity Press.

Best, J. (2009) What policy-makers want from research; what researchers want to tell them, Journal of Policy Research in Tourism, Leisure and Events, 1(2), 175-178.

Bette, K-H. (1989) Korperspuren; Zur Semantik und Paradoxie moderner Korperlichkeit. Berlin/New York: Walter de Gruyter. 
Bevir, M., \& Rhodes, R. A. W. (2010). The state as cultural practice. Oxford: Oxford University Press.

Bevir, M., \& Rhodes, R. A. W. (2011). The stateless state. In M. Bevir (Ed.), The SAGE handbook of governance (pp. 203-217). London: Sage.

Bevir, M., \& Rhodes, R. A. W. (2018). Routledge handbook of interpretive political science. London, Routledge.

Booth, D. and Thorpe, H. (eds) (2007) Berkshire Encyclopaedia of Extreme Sports. Great Barrington. MA: Berkshire Reference Works.

Bratman, G. N., Daily, G.C., Levy, B.J. and Gross, J.J. (2015) The benefits of nature experience: improved affect and cognition, Landscape and Urban Planning, 138 (6) (2015), pp. 41-50.

Breivik G. (1996) Personality, sensation seeking and risk taking among Everest climbers. International Journal of Sport Psychology, 27, 308-320.

British Broadcasting Corporation (BBC) Allow boxing in prisons, Ministry of Justice report says, available at: https://www.bbc.co.uk/news/uk-45141149 [accessed on November 30th 2018].

Butts, S. (2001) Good to the last drop: Understanding surfers' motivations. Sociology of Sport Online (SOSOL), 4,1, 1 -7.

Cabinet Office/DCMS (2002) Game Plan, London, Cabinet Office/DCMS

Caron AV, Hausenblas HA, Estabrooks PA. (2003) Motivational theories of exercise and physical activity. In: The Psychology of Physical Activity. Boston, MA: McGraw-Hill, 171182. 
Camoletto, R. F., Sterchele, D., \& Genova, C. (2015). Managing alternative sports: new organisational spaces for the diffusion of Italian parkour. Modern Italy, 20(3), 307-319.

Countryside Agency (2005) Demand for outdoor recreation in the English National Parks, Cheltenham, Countryside Agency.

Comley, V. and Mackintosh, C. (2014) Reconomics: The Economic Impact of Outdoor Recreation in the UK - The Evidence, Liverpool, Liverpool John Moores University/SRA.

Cramer JT. (2008) Bioenergetics of exercise and training. In: Essentials of Strength Training and Conditioning. 3rd Edition. Baechle TR and Earle RW, eds. Champaign, IL: Human Kinetics, 21-39.

Crum, B. (1993) Conventional Thought and Practice in Physical Education: Problems of Teaching and Implications for Change, Quest, 45, 339-356.

Crum, B. (1994) Changes in Movement Culture: Challenges for Sport Pedagogy. Proceedings from the AISEP conference, volume 2, Sport Leisure and Physical Education, Trends and Developments.

Crocket, H. (2013) 'This is men's ultimate':(Re) creating multiple masculinities in elite open Ultimate Frisbee. International Review for the Sociology of Sport, 48(3), 318-333.

Crocket, H. (2016) An ethic of indulgence? Alcohol, Ultimate Frisbee and calculated hedonism. International review for the sociology of sport, 51(5), 617-631.

Cutforth, C. (2017) ' ', in Wilson, R. and Platts, C. (eds.) Managing and Developing Community Sport, London, Routldege, pp.

Department of Culture, Media and Sport (DCMS) (2015) Sporting Nation, London, DCMS.

Department of Culture, Media and Sport (2015a) A New Strategy for Sport: A Consultation Paper, London, DCMS. 
Department for the Environment, Farming and Rural Affairs (DEFRA) (2018) A Green Future: Our 25 Year Plan to Improve the Environment, London, DEFRA.

Eichberg, H. (1998) Body Cultures: Essays on sport. Space and identity. London: Routledge.

Elias, N., and E. Dunning (1986) Quest for excitement: sport and leisure in the civilizing process. Oxford: Basil Blackwell.

Featherstone, M. (1991) Consumer Culture and Postmodernism. London: Sage.

Focht, B.C. (2009) Brief walks in outdoor and laboratory environments: Effects on affective responses, enjoyment, and intentions to walk for exercise. International Journal of Stress Management 14 (1), 88-98.

Freeman, E., Akhurst, Bannigan,K., and James, H. (2016) "Benefits of walking and solo experiences in UK wild places" Health Promotion International, 31 (3), 1-9.

Freudenberg, P, and Arlinghaus. R. (2009) "Benefits and constraints of outdoor recreation for people with physical disabilities: inferences from recreational fishing", Leisure Sciences, 32(1), $55-71$.

Fitzpatrick, (2013) I felt Like I was a Road Runner, Telegraph, $10^{\text {th }}$ May 2013, available at: https://www.telegraph.co.uk/lifestyle/wellbeing/outdoors/10050064/Tough-Mudder-2013-Ifelt-like-I-was-Road-Runner.html [accessed 22nd May 2018].

Focht, B.C. (2009). Brief walks in outdoor and laboratory environments: Effects on affective responses, enjoyment, and intentions to walk for exercise. International Journal of Stress Management, 14 (1), 88-98.

Giddens, A (1991) Modernity and self-identity. Self and society in the late modern age. Oxford: Polity Press. 
C.J. Gidlow, C.J., Jones,M.J. Hurst,G.,Masterson, D., Clark-Carter,D., Tarvainen,M.P., Smith, G., Nieuwenhuijsen, M. (2016) Where to put your best foot forward: psycho-physiological responses to walking in natural and urban environments, Journal of Environmental Psychology, 45 (3), pp. 22-29,

Gilchrist, P. and Wheaton, B. (2011) Lifestyle sport, public policy and youth engagement: examining the emergence of parkour, International Journal of Sport Policy and Politics, 3 (1), $109-131$.

Gladwell, V.F., Brown, D.K., Wood, C., Sandercock, G.R. Barton, J.L. (2013) The great outdoors: how a green exercise environment can benefit us all. Extreme Physiology \& Medicine, 2, 3-13.

Green, K. (2010) Key Themes in Youth Sport. London: Routledge.

Griggs, G. (2009a) 'Just a sport made up in a car park': The soft landscape of ultimate Frisbee. Social and Cultural Geography. 10, 7, 757 - 770.

Griggs, G. (2009b) When a ball dreams, it dreams it's a Frisbee': The emergence of aesthetic appreciation within Ultimate Frisbee. Sport in society. 12 (10), 1317 - 1326.

Griggs, G. (2011) This must be the only sport in the world where most of the players don't know the rules': Operationalising Self refereeing in UK Ultimate Frisbee, Sport in Society, 14, $1,97-110$.

Griggs, G. (2012) Why have alternative sports grown in popularity in the UK? Annals of Leisure Research, 15(2), 180-187.

Giulianotti, R. (1995) Participant observation and research into football hooliganism: reflections on the problems of entree and everyday risks. Sociology of Sport Journal, 12 (1), $1-20$. 
Hagger M, Chatzisarantis N. (2005) The Social Psychology of Exercise and Sport. New York, NY: Open University Press.

Herzog, T., Chen, H., Primeau, J. (2002) Perception of the restorative potential of natural and other settings, Journal of Environmental Psychology, 22 (3), 295-306.

Henley Centre (2005) Outdoor Recreation Strategy, London, Natural England.

Herzog, T., Black, A., Fountaine, K., Knotts, D. (1997) Reflection and attentional recovery as distinctive benefits of restorative environments, Journal of Environmental Psychology, 17 (2), $165-170$

Herzog T.R., Strevey, S. J. (2008) Contact with nature, sense of humor, and psychological wellbeing. Environment and Behaviour, 40 (6) 747-776.

Hindley, D. (2018) "More Than Just a Run in the Park": An Exploration of Parkrun as a Shared Leisure Space, Leisure Sciences, (iFirst publication).

Holland, J. and Thomson, R. (1999) Respect youth values: identity, diversity and social change. ESRC Children 5-16 Research Programme Briefing. London: ESRC.

Howell, O. (2008) Skateparks as neoliberal playground. Space and culture, 11 (4), 475-496.

Jackson, P., Stevenson, N. and Brooks, K. (2001) Making sense of men's magazines. Cambridge: Polity Press.

Kennedy, S. (2012) Playing Dirty. Outside. Accessed at https://www.outsideonline.com/1908376/playing-dirty [accessed on May 22nd 2018].

Kilpatrick M, Hebert E, Jacobsen D. (2002) Physical activity motivation: A practitioner's guide to self-determination theory. JOPERD, 73 (4), 36-41.

Kuo, F. and Sullivan, W. (2001) Aggression and Violence in the Inner City: Effects of Environment via Mental Fatigue. Environment and Behavior 33(4): 543-71. 
Laursen P. B. (2010) Training for intense exercise performance: High-intensity or high-volume training? Scandinavian Journal of Medicine, Science and Sports, 20 (2), 1-10.

L'Aoustet, O. and Griffet, J., (2001) The experience of teenagers at Marseilles' skate park: emergence and evaluation of an urban sports site. Cities, 18 (6), 413-418.

Louv, R. (2005). Last child in the woods: Saving our children from nature-deficit disorder. North Carolina. Algonquin.

Lubbe. H. (1988) Mencshen im Jahr 2000. Rahmenbedinggungen fur die kunftige Entwicklung des Sports, In K-H. Giesler, O. Grupe and K. Heinmann (Hrsg.) Dokumentation des Kongresses 'Menschen im Sport 2000'. Schorndorf: Hofmann 32 - 43.

Mackintosh, C. I.., Darko, N., \& May-Wilkins, H. (2015). Unintended outcomes of the London 2012 Olympic Games: Local voices of resistance and the challenge for sport participation leverage in England. Leisure Studies, 35 (4), 454-469.

Mackintosh, C. (2018) Challenging the status quo, Sport Management, 32 (3), London, Leisure Media. Available at:

http://www.sportsmanagement.co.uk/digital/index1.cfm?mag=\&codeid=3447\&linktype=hom epage \&ref $=\mathrm{n}$ [accessed on November $\left.11^{\text {th }} 2018\right]$.

Meek, R. (2018) A Sporting Chance: An Independent Review of Sport in Youth and Adult Prisons, London, Ministry of Justice.

Midol, N (1993) Cultural dissents and technical innovations in the 'whiz' sport, International Review for the Sociology of Sport, 28 (1), 23 - 32.

Midol, N. and Broyer, G. (1995) Towards and anthropological analysis of new sport cultures: the case for whiz sports in France, Sociology of Sport Journal, 12, $204-212$. 
Martin, H. (2013) In big-money obstacle runs, mud and risks are par for the course. Los Angeles Times. Retrieved from http://articles.latimes.com/2013/sep/14/ business/la-fi-mudruns-20130914 [accessed May $22^{\text {nd }} 2018$ ).

Morris, N. (2003) Health, wellbeing and open space: Literature Review. OPENspace: Research for the Inclusive Access to Outdoor Environments.

Mort, F. (1988) Boy's Won? Masculinity, style and popular culture, In J. Rutherford (ed) Male order: Unwrapping masculinity. London: Lawrence and Wishart.

Mullins, N. (2012) Obstacle Course Challenges: History, Popularity, Performance Demands, Effective Training, and Course Design, Journal of Exercise Physiology, Volume 15 Number 2, 113-125.

Nettleton, S., \& Hardey, M. (2006). Running away with health: the urban marathon and the construction of 'charitable bodies'. Health, 10(4), 441-460.

O'Brien, L. and Forester, J. (2017) Fun and Fitness in the Forest: Monitoring and evaluation of the three- year Active Forest pilot programme, Report for Sport England, Forest Research, Farnham.

Ojala, A., Korpela, K., Tyrväinen, L, Tiittanen, P. and Lanki, T. (2018) Restorative effects of urban green environments and the role of urban-nature orientedness and noise sensitivity: A field experiment, Health and Place (in press, open access).

Outdoor Industries Association (OIA) (2015) Getting Active Outdoors, Sport England/OIA, London.

Plante, T.G., Gores, C., Brecht, C., Carrow, J., Imbs, A, Willemsen, E. (2007) Does exercise environment enhance the psychological benefits of exercise for women? International Journal of Stress Management. 14 (1), 88-98. 
Pretty, J., Peacock, J., Hine, R. Sellens, M., South, N., Griffin, M. (2007), Green Exercise in the UK Countryside: Effects on Health and Psychological Wellbeing, and Implications for Policy \& Planning. Journal of Environmental Planning Management, 50 (2), 211-31.

Pretty, J., Peacock, J. \& Sellens, Griffin, M. (2005), The mental and physical health outcomes of green exercise. International Journal of Environmental Health Research, 15 (5), 319-37.

Pretty, L., Griffin, M, Sellens, N. \& Pretty, C. (2003) Exercise and Diet in Physical and Emotional Wellbeing and Implications for Public Health Policy. CES Occasional Paper 20031, University of Essex.

Pretty J, Griffin M, Sellens M, Pretty and Green, C. (2003) Exercise: Complementary Roles of Nature, Exercise and Diet in Physical and Emotional Wellbeing and Implications for Public Health Policy. Colchester: CES Occasional Paper 2003-1. University of Essex;

Prout, A. (2000) Children's Participation: Control and Self-realisation in British Late Modernity, Children and Society, 14, 304-315.

Public Health England (2014) Everybody Active, Every Day report, London, Public Health England.

Puddle, D., Wheaton, B., \& Thorpe, H. (2018). The glocalization of parkour: a New Zealand/Aotearoa case study, Sport in Society, 1-18.

Reuter B.H. and Hagerman P.S. (2008) Aerobic endurance exercise training. In: Essentials of Strength Training and Conditioning. 3rd Edition. Baechle TR and Earle RW, eds. Champaign, IL: Human Kinetics, 489-503.

Rinehart, R. and Sydnor, S. (eds) (2012) To the extreme: Alternative sports, Inside and out. Albany: SUNY Press.

Roberts G. C., Treasure D.C. and Conroy D.E. (2007) Understanding the dynamics of motivation in sport and physical activity: An achievement goal interpretation. In: Handbook 
of Sport Psychology.3rd Edition. Tenenbaum G and Eklund RC, eds. Hoboken, NJ: John Wiley \& Sons,

Rossi B, and Cereatti L. (1993) The sensation seeking in mountain athletes as assessed by Zuckerman's Sensation Seeking Scale. International Journal of Sport Psychology, 24(4), 417431.

Rink, J.E. (2005) (5 $5^{\text {th }}$ ed.) Teaching Physical Education for Learning. St. Louis, MI: McGrawHill Humanities.

Rutter, M. and Smith, D.J. (1995) Towards causal explanations of time trends in psychosocial disorders of young people. In Psychosocial Disorders of Youth, Rutter M, Smith DJ (eds). John Wiley and Sons: New York.

Shipway, R. and Jones, I. (2008) The Great Suburban Everest: An 'insiders' perspective on experiences at the 2007 Flora London Marathon. Journal of Sport \& Tourism, 13(1), 61-77.

Shipway, R., \& Holloway, I. (2010). Running free: Embracing a healthy lifestyle through distance running. Perspectives in public health, 130 (6), 270-276.

Shipway, R., Holloway, I., \& Jones, I. (2013). Organisations, practices, actors, and events: Exploring inside the distance running social world. International Review for the Sociology of Sport, 48(3), 259-276.

Shulze, G. (1992) Die Erlebnisgesellschaft. Frankfurt/New York: Campus.

Sport England (2016) [online] Active people survey. Available from: http://www.sportengland.org/research/active_people_survey/active_people_survey_1.aspx [Accessed 15 May 2016].

Sport England (2016a) Towards an Active Nation, London, Sport England. 
Sport England (2017) [online] Active people survey. Available from: http://www.sportengland.org/research/active_people_survey/active_people_survey_1.aspx [Accessed 15 May 2017].

Sport and Recreation Alliance (2014) Reconomics, London, Sport and Recreation Alliance.

Sport and Recreation Alliance (2017) Reconomics Plus, London, Sport and Recreation Alliance.

Stebbins, R. (1992) Amateurs, Professionals and Serious Leisure. London: McGill Queens.

Stebbins, R. A. (1997). Casual leisure: A conceptual statement. Leisure studies, 16(1), 17-25.

Stevinson, C. and Hickson, M. (2014) Exploring the public health potential of a mass community participation event, Journal of Public Health, 36 (2), 268-274,

ten Brink, P., Mutafoglu,K., Schweitzer,J.P., Kettunen, M., Twigger-Ross,C., Baker,J., Kuipers, J., Emonts,M., Tyrväinen,L., Hujala,T., Ojala, (2016) A. The health and social benefits of nature and biodiversity protection. A Report for the European Commission (ENV.B.3/ETU/2014/0039) Institute for European Environmental Policy, London/Brussels.

Tomlinson, A., Ravenscroft, N., Wheaton, B., and Gilchrist, P., (2005) [online]. Lifestyle sport and national sport policy: an agenda for research [online]. Report to Sport England (March). Available from: http:// www.sportengland.org/search.aspx?query=lifestyle+ sport+and+national+sport+policy [Accessed 7 February 2018].

Thompson, C. and Aspinall, P. A. (2011), Natural Environments and their Impact on Activity, Health, and Quality of Life. Applied Psychology: Health and Wellbeing, 3: pp. 230-260.

Triggs, J. (2008) The Toughest Race on Earth. Accessed at http://www.express.co.uk/expressyourself/33358/The-toughest-race-on-earth [Accessed 7 February 2018]. 
UK Parliament (2015) Hansard Parliament Debate Record from Westminster Hall - Outdoor Recreation, $\quad 28^{\text {th }} \quad$ October $\quad 2.30 \mathrm{pm}, \quad 2015, \quad$ available $\quad$ at: https://hansard.parliament.uk/commons/2015-10-

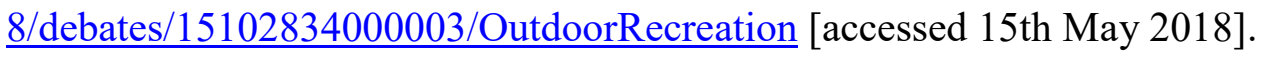

Wagenaar, H. (2011). Meaning in action: interpretation and dialogue in policy analysis. New York: M. E. Sharpe.

Wang, N. 1999. Rethinking Authenticity in Tourism Experiences. Annals of Tourism Research, 26 (2), pp.349-370.

Walvin, J. (ed) (1975) Leisure and Society 1830 - 1950. London: Longman.

Whannel, G. (2002) Media Sport Stars: Masculinities and moralities. London: Routledge.

Wheaton, B. (2000) Just do it: Consumption, commitment, and identity in the windsurfing subculture, Sociology of Sport Journal, 17, 254 - 274.

Wheaton, B. (ed) (2004) Understanding Lifestyle Sports: Consumption, identity and difference. London: Routledge.

Wheaton, B. (2007) After sport culture: rethinking sport and post-subcultural theory. Journal of sport and social issues, 31 (3), 283-307.

World Heart Foundation (WHF) (2011) [online] Cardio Vascular Disease. Available from: http://www.bhf.org.uk/heart-health/conditions/cardiovascular-disease.aspx [Accessed 19 July 2017].

Zuckerman, M. (1983) Sensation seeking and sports. Personality and Individual Difference, 4 (3), 285-293.

Zuckerman M. (1994) Behavioural Expressions and Biosocial Bases of Sensation Seeking. New York, NY: Cambridge Press, 